\title{
Online Supplement for "An Approach for Analyzing and Managing Flexibility in Engineering Systems Design Based on Decision Rules and Multistage Stochastic Programming”
}

by Cardin, M.-A., Xie, Q., Ng, T.S., Wang, S. and Hu, J. (2016)

Table I: Summary of notation

\begin{tabular}{|c|c|c|c|}
\hline Variable & Definition & Variable & Definition \\
\hline$T$ & $\begin{array}{l}\text { Number of time periods in the planning } \\
\text { horizon }\end{array}$ & $\xi_{t}$ & $\begin{array}{l}\text { Realization of uncertainty / Amount } \\
\text { of food waste collected in year } t\end{array}$ \\
\hline$\eta_{t}$ & $\begin{array}{l}\text { Amount of other organic waste collected } \\
\text { in year } t\end{array}$ & $x_{t}$ & Option chosen for in time $t$ \\
\hline$\pi$ & Discount rate & $\xi$ & A scenario of uncertainty \\
\hline$\Omega$ & Set of all possible uncertainty scenarios & $\xi^{k}$ & $k^{\text {th }}$ scenario of uncertainty \\
\hline$p^{k}$ & Probability of scenario $k$ & $X_{t}$ & Set of feasible options in period $t$ \\
\hline$x$ & Option sequence & $X$ & Set of all feasible option sequences \\
\hline$\delta$ & Decision rule & $\theta$ & Set of parameters of the decision rule \\
\hline$\delta_{\theta}$ & Decision rule with parameter $\theta$ & $\mathcal{D}$ & Set of all mappings from $\Omega$ to $X$ \\
\hline$\xi[t]$ & $\begin{array}{l}\text { The history of the uncertainty realization } \\
\text { up to period } t\end{array}$ & $r_{t}\left(\delta_{\theta}\left(\xi_{[t]}^{k}\right)\right.$ & $\begin{array}{l}\text { Profit function in period } t \text { in scenario } \\
k\end{array}$ \\
\hline$\delta_{\theta}(\xi)$ & $\begin{array}{l}\text { The sequence of options chosen } \\
\text { following the decision rule }\end{array}$ & $\delta_{\theta}\left(\xi_{[t]}^{k}\right)$ & $\begin{array}{l}\text { The option chosen at time } t \text { in } \\
\text { scenario } k\end{array}$ \\
\hline $\mathrm{r}\left(\delta_{\theta}(\xi), \xi\right.$ & Total profit function & $\Delta$ & A subset of $\mathcal{D}$ \\
\hline$\delta^{*}$ & The optimal decision rule & $\theta^{k}$ & $\begin{array}{l}\text { A replication of the decision rule } \\
\text { parameters in scenario } k\end{array}$ \\
\hline $\bar{\theta}$ & The average of $\theta^{\xi}$ over its $K$ replications & $\lambda$ & Lagrange multipliers \\
\hline$\lambda^{k}$ & Lagrange multipliers for scenarios $k$ & $L\left(\delta_{\theta}, \lambda\right)$ & Lagrangian of the original problem \\
\hline$D(\lambda)$ & $\begin{array}{l}\text { Optimal value of the Lagrangian } \\
\text { relaxation problem with the Lagrange } \\
\text { multiplier } \lambda\end{array}$ & $Z^{L D}$ & $\begin{array}{l}\text { Optimal value of the Lagrangian dual } \\
\text { problem }\end{array}$ \\
\hline$t_{i}$ & Step size in $i$ th iteration in the gradient & $r_{t}$ & Profit function \\
\hline
\end{tabular}




\begin{tabular}{|c|c|c|c|}
\hline & method & & \\
\hline$R_{t}$ & Revenue function & $C_{t}$ & Cost function \\
\hline$P_{t}$ & $\begin{array}{l}\text { The penalty function due to the capacity } \\
\text { shortage }\end{array}$ & $f_{t}$ & Capacity shortage of AD \\
\hline$f_{t}^{\prime}$ & Capacity shortage of gasifier & $n$ & Number of jumps from each node \\
\hline$\xi_{t+1, j}$ & $\begin{array}{l}\text { Food waste amount in node order } j \text { of the } \\
\text { following } n \text { nodes at time interval } t+1\end{array}$ & $p_{j}$ & $\begin{array}{l}\text { Probability of the state in node order } \\
j\end{array}$ \\
\hline$\alpha$ & The severity level of the current capacity & $\beta$ & $\begin{array}{l}\text { The number of modules expanded } \\
\text { each time }\end{array}$ \\
\hline$o_{u}$ & Capacity of the unit module & $e_{t}^{k}$ & $\begin{array}{l}\text { Binary variables indicating whether } \\
\text { to expand in year } t \text { in scenario } k\end{array}$ \\
\hline$h_{t}^{k}$ & The amount of capacity to be added & $\varepsilon$ & $\begin{array}{l}\text { The number of modules initially } \\
\text { installed in } \mathrm{AD}\end{array}$ \\
\hline$\varepsilon^{\prime}$ & The capacity of gasifier initially installed & $x_{M}$ & $\begin{array}{l}\text { The maximum number of modules } \\
\text { allowed to be installed in } \mathrm{AD}\end{array}$ \\
\hline$y_{M}$ & $\begin{array}{l}\text { The maximum capacity allowed to be } \\
\text { installed in gasifier }\end{array}$ & $x_{f}$ & $\begin{array}{l}\text { The capacity of the baseline } \\
\text { inflexible design }\end{array}$ \\
\hline$y_{t}$ & Capacity of gasifier in year $t$ & $\gamma_{1_{t}}, \gamma_{2}, \gamma_{3}$ & $\begin{array}{l}\text { Coefficients of the linear decision } \\
\text { rule for gasifier }\end{array}$ \\
\hline$T_{t}$ & $\begin{array}{l}\text { Tipping fee function of hybrid WTE } \\
\text { system }\end{array}$ & $R_{A_{t}}$ & $\begin{array}{l}\text { Revenue function of } \mathrm{AD} \text { in hybrid } \\
\text { WTE system }\end{array}$ \\
\hline$R_{G_{t}}$ & $\begin{array}{l}\text { Revenue function of gasifier in hybrid } \\
\text { WTE system }\end{array}$ & $C_{A_{t}}$ & $\begin{array}{l}\text { Cost function of AD in hybrid WTE } \\
\text { system }\end{array}$ \\
\hline$C_{G_{t}}$ & $\begin{array}{l}\text { Cost function of gasifier in hybrid WTE } \\
\text { system }\end{array}$ & $S_{t}$ & Set of state variables in period $t$ \\
\hline$R_{t}\left(S_{t-1}\right)$ & $\begin{array}{l}\text { Function of total reward starting from } \\
\text { period } t \text { until the last period }\end{array}$ & $\phi_{t}(\cdot)$ & $\begin{array}{l}\text { Basis function in the linear value } \\
\text { function approximation in ADP }\end{array}$ \\
\hline $\boldsymbol{\rho}_{t}$ & $\begin{array}{l}\text { Vector of weights of in the linear value } \\
\text { function approximation in ADP }\end{array}$ & $H$ & $\begin{array}{l}\text { Number of iterations in LSPI } \\
\text { algorithm }\end{array}$ \\
\hline$I$ & $\begin{array}{l}\text { Number of sample paths generated in } \\
\text { each iteration in LSPI algorithm }\end{array}$ & & \\
\hline
\end{tabular}

* The variables with superscript $\mathrm{k}$ correspond to the variables in scenario k. 
Table II: List of assumptions for WTE system

\begin{tabular}{|c|c|c|}
\hline Parameters & Value & Definition \\
\hline $\mathrm{T}$ & 9 & Time span of the system considered \\
\hline$p$ & $70 \%$ & Purity ratio of the food waste feedstock \\
\hline$\tau$ & $10 \%$ & Residue ratio of the $\mathrm{AD}$ process \\
\hline$z_{1}$ & $\mathrm{~S} \$ 22,469 / \mathrm{tpd}^{*}$ & $\begin{array}{l}\text { Revenue from electricity generation per tpd food waste processed } \\
\text { in } \mathrm{AD} \text { unit }\end{array}$ \\
\hline$z_{2}$ & $\mathrm{~S} \$ 1,336 / \mathrm{tpd}$ & Revenue from compost per tpd waste processed in AD unit \\
\hline$z_{3}$ & $\mathrm{~S} \$ 28,105 / \mathrm{tpd}$ & Revenue from tipping fee per tpd waste collected \\
\hline$z_{4}$ & $\mathrm{~S} \$ 700 / \mathrm{tpd}$ & Transportation cost per tpd food waste collected \\
\hline$z_{5}$ & $\mathrm{~S} \$ 75,000 / \mathrm{tpd}$ & Capacity installation cost per unit AD capacity \\
\hline$z_{6}$ & $\mathrm{~S} \$ 816 / \mathrm{tpd}$ & Land rental cost per unit capacity installed \\
\hline$z_{7}$ & $\mathrm{~S} \$ 204 / \mathrm{tpd}$ & Land rental cost per unit capacity reserved \\
\hline$z_{8}$ & $\mathrm{~S} \$ 675 / \mathrm{tpd}$ & Labor cost per unit capacity of $\mathrm{AD}$ unit \\
\hline$Z_{9}$ & $\mathrm{~S} \$ 225 / \mathrm{tpd}$ & Maintenance cost per unit capacity of AD unit \\
\hline$z_{10}$ & $\mathrm{~S} \$ 28,105 / \mathrm{tpd}$ & Disposal cost per tpd waste disposed in landfill \\
\hline$\pi$ & $8 \%$ & Discount rate \\
\hline$o_{u}$ & 30 tpd & Capacity of an unit module \\
\hline$p^{\prime}$ & $70 \%$ & Purity ratio of the other organic waste feedstock \\
\hline$\tau^{\prime}$ & $20 \%$ & Residue ratio of the gasifier \\
\hline$z_{11}$ & $\mathrm{~S} \$ 62,678 / \mathrm{tpd}$ & $\begin{array}{l}\text { Revenue from electricity generation per tpd waste processed in the } \\
\text { gasifier }\end{array}$ \\
\hline$z_{12}$ & $\mathrm{~S} \$ 5,840 / \mathrm{tpd}$ & $\begin{array}{l}\text { Total of labor, admin, maintenance cost per tpd waste treated in } \\
\text { the gasifier }\end{array}$ \\
\hline$z_{13}$ & $\mathrm{~S} \$ 2,920 / \mathrm{tpd}$ & Cost of the RDF process per tpd of waste treated in the gasifier \\
\hline
\end{tabular}


$z_{14} \quad \mathrm{~S} \$ 96,970 /$ tpd $\quad$ Capital cost of per tpd capacity of the gasifier

*tons per day (tpd) is used to as the unit of waste amount and the capacity of the AD plant.

Table III: Parameters of the main uncertainty drivers in the case study

\begin{tabular}{cccc}
\hline Parameters & Definition & Food waste & Other organic waste \\
\hline$\mu$ & Annual growth rate & $14.1 \%$ & $6.0 \%$ \\
$\sigma$ & Volatility & $16.4 \%$ & $4.1 \%$ \\
$\xi_{0} / \eta_{0}$ & Waste amount in year 0 & $191 \mathrm{tpd}$ & $2,823 \mathrm{tpd}$ \\
\hline
\end{tabular}

